\title{
An empowering approach to crisis intervention and brief treatment with preschool children
}

Katherine Tyson McCrea

Loyola University Chicago, ktyson@luc.edu

Follow this and additional works at: https://ecommons.luc.edu/socialwork_facpubs

Part of the Social Work Commons

\section{Recommended Citation}

McCrea, Katherine Tyson. "An Empowering Approach to Crisis Intervention and Brief Treatment for Preschool Children." Families in Society, vol. 80, no. 1 (1999): 64-77.

This Article is brought to you for free and open access by the Faculty Publications and Other Works by Department at Loyola eCommons. It has been accepted for inclusion in Social Work: School of Social Work Faculty Publications and Other Works by an authorized administrator of Loyola eCommons. For more information, please contact ecommons@luc.edu.

\section{(c) $($ () $\ominus$}

This work is licensed under a Creative Commons Attribution-Noncommercial-No Derivative Works 3.0 License. (C) 1999 Families International, Inc. 


\title{
An Empowering Approach to Crisis Intervention and Brief Treatment for Preschool Children*
}

\author{
by Katherine Tyson
}

\begin{abstract}
This paper presents an approach to crisis intervention and brief treatment for young children based on the new psychology, intrapsychic humanism. After presenting central theoretical principles, these principles are applied and treatment guidelines demonstrated in the treatment process of a three-year-old child named Paul. The research design for the case study is naturalistic, uses qualitative methods of data analysis, and draws from the heuristic paradigm (a postpositivist metatheory of social and behavioral research).
\end{abstract}

YOUNG CHILDREN OFTEN are confronted with stressful events that have profound implications for their lives and can precipitate psychological crises. For example, their parents may divorce or die, the child or those close to the child may be injured or develop a serious illness, or the child may have been abused or neglected and need to be removed from the home and placed in foster care (Fatout, 1993; Freud, 1952; Freud \& Burlington, 1943; Zambelli \& Clark, 1994). Although there is a growing body of research about children in crisis, including their capacity to report the crisis event (Sorenson \& Snow, 1991) and the often devastating long-term psychological consequences of trauma (Berliner $\&$ Wheeler, 1987; Famularo, Kinschereff, \& Fenton, 1990; Juhasz, 1995; Lewis, 1992; Terr, 1990), that research generally does not offer social workers guidelines for how to respond to children in crisis. Moreover, practice guidelines that have been presented generally do not include evaluations of treatment responses. In particular, there is a dearth of research about individual psychosocial treatment of children under six. This paper presents and evaluates an approach to crisis intervention with preschool children based on the new psychology, intrapsychic humanism (Pieper \& Pieper, 1990).
Intrapsychic humanism offers a compassionate and rigorously scientific reconceptualization of child development, psychopathology, and treatment and leads to an understanding of children's subjective experience and to effective clinical interventions with children and families (Ishibashi, 1991; Pieper \& Pieper, 1992; Tyson, 1991). ${ }^{1}$ This approach is helpful for treating clients deemed untreatable under other approaches (Pieper \& Pieper, 1995), and treatment principles based on intrapsychic humanism have been used effectively in treating clients of all age groups, backgrounds, and diagnostic categories. Intrapsychic humanism offers a therapeutic approach that can be used in treating individuals, and families, and for-group and milieu therapy. Evaluations of treatments based on intrapsychic humanism have been published previously (Pieper \& Pieper, 1995; Tyson, 1995). This new psychology is increasingly attracting the interest of scholars and practitioners in this country and abroad (Fenby, 1992; Tyson, 1996a, 1996b). In addition to reconceptualizing child development, psychopathology and treatment, the Piepers also have developed a compassionate and effective approach to parenting that has been tested in numerous settings and will be available in published form soon (Pieper \& Pieper, 1999).

\footnotetext{
* Previous versions of this article were presented at 1) The International Conference on Innovations in Clinical Social Work Practice, co-sponsored by the School of Social Work, Loyola University, the Universitta Cattolica, Milan, Italy, and the School of Social Work, L.U.M.S.A. Rome, Italy, in May 1993 and 2) The National Association of Social Workers, Annual Meeting, Philadelphia, Pennsylvania, October 1995.
}

Families in Society: The Journal of Contemporary Human Services Copyright 1999 Familles International, Inc. 
Current thinking and practice in the field has focused almost exclusively on helping young children by treating their parents (Zambelli \& Clark, 1994). Of course treatment planning is an individually-tailored process that takes into account the needs of the family, individuals within the family, and the social worker's practice context. Under many circumstances, it might be preferable to use family therapy or to offer parental counseling to aid both parents and child. At the same time, children can benefit from direct service to a much greater degree than is generally recognized. Certainly parental counseling or therapy are important adjuncts to individual child treatment, but sometimes parents refuse help for themselves and are willing to bring their child for treatment. Young children usually want help even if their parents do not. Moreover, even if the parents do agree to get help, treating them alone may not sufficiently aid the child. For all these reasons, it is important to know how to heip children through direct individual treatment. My focus on individual counseling does not imply that other social services for the child and family are unimportant. Rather, a child often needs psychological help before s/he can make use of other social services. For example, a child experiencing a crisis in her/his home may become acutely afraid of starting a new play group, as we will see in the example of Paul. Crisis treatment includes helping the child and her/his family to benefit from other social supports. Increasingly, there are sharp limits on the number of crisis treatment sessions that can be offered to clients, especially child clients, and so one of the most important issues the clinical social worker faces is how to make the best use of those sessions. The principles to be described in concert with the case example will address this contemporary reality as well.

\section{Approaches to Crisis Intervention}

A psychological crisis has traditionally been understood as a subjective state of acute distress, precipitated by a loss or the threat of a loss (the crisis event). In a psychological crisis state, the individual's psychological and sometimes environmental resources are so overwhelmed that the individual cannot adequately care for her/himself (Lindeman, 1965; Parad \& Parad, 1980; Rapoport, 1970). Crisis intervention is defined as an immediate, short-term, and sometimes intensive treatment process that restores the individual to her/his prior level of functioning and also aims to foster a sound resolution of the psychological crisis (Boyd-Webb, 1994; Lindeman, 1965;
Parad \& Parad, 1980).

Traditional approaches to crisis intervention have the cardinal principle of stimulating the client's problemsolving capacity so as to restore the client's best level of functioning. This generally implies fostering insight into the meaning of the precipitating event and guiding the client to more adaptive resolutions of interpersonal problems associated with it (Parad \& Parad, 1980; Rapaport, 1970). In traditional therapies, the relationship with the therapist is intentionally of secondary importance. The crisis therapist aims to foster a positive transference, interprets negative transference experience only with the aim of short-circuiting its obstructiveness, and intentionally aims to prevent a more intensive transference experience, which is regarded as regressive (encouraging "dependency") (Rapoport, 1970).

While published research on crisis intervention with preschool children is sparse, therapists using traditional approaches have found them highly problematic with preschool children. In fact, Kelly and Wallerstein (1977) stated that direct treatment of preschool children is not effective, and that the therapist's efforts should instead be directed toward helping parents respond better to children's needs. Generally, direct crisis treatment of preschool children has been considered unworkable for two reasons. First, traditional crisis intervention relies heavily on insight and problem solving as a means of restoring the client's functioning (Parad \& Parad, 1980; Rapaport, 1970). Preschool children are thought to lack the cognitive capacity to benefit from insight-oriented treatment, and their age-appropriate cognitive limitations generally preclude them from being able to participate in a sustained logical problem-solving process (Cheyne \& Rubin, 1983). Second, an important aspect of traditional crisis intervention is helping the client alter those environmental stressors that are amenable to change (e.g., taking shelter from an abusive spouse, getting adequate medical care for a serious health problem). Although young children do have a significant impact on their families, they cannot change or leave their environment in the way adults can.

By contrast, because the therapeutic action in intrapsychic humanism does not rely on cognition, the ageappropriate cognitive limitations of children under six present no problem in this treatment approach. Intrapsychic humanism's central focus is on the internal capacity for constructive self-regulation, which is acquired through the caregetting pleasure a child or client experiences in a caregiving relationship. The capacity for constructive self-regulation refers to the client's ability to 
have a stable inner well-being, make self-caretaking choices, and reliably pursue those choices. ${ }^{2}$ According to intrapsychic humanism, constructive self-regulation is acquired as a child or client discovers that s/he can bring about inner well-being by engaging the caregiver's (parent's or therapist's) caregiving responses. Every human being seeks to acquire a capacity for constructive self-regulation via being able to engage a caregiver's unconditional, deep pleasure in providing care. For instance, when an infant cries to signal to the caregiver that $s / h e$ is hungry, the caregiver's responsive feeding has empowering meaning for the infant: namely, that s/he can bring about the pleasure of satiety and physical comfort, and, just as importantly, that s/he is so appealing and worthwhile that $\mathrm{s}$ /he can cause the caregiver to want to provide such profoundly pleasurable satisfaction (Pieper \& Pieper, 1990). Accordingly, by being able to regulate the caregiver's care, the child's capacity for constructive selfregulation develops - the child learns to treat her/himself with the same good care s/he receives.

How does it happen that children do not develop stable constructive self-regulation? Children are born believing that their parents are perfect and give them perfect care. They have an inborn ideal of caregiving mutuality, that, when matched with optimal parental care, creates psychological structure that brings about stable inner well-being and self-regulation - the child treats her/himself as well as s/he was cared for by the parents. All caregivers try to and believe they do provide the best care for their children. Yet an observer can see that some caregivers can be, unknowingly and unintentionally, negligent or abusive. Even though abusive or negligent parental care does not match the infant's inborn ideal, the infant, lacking a standard of comparison and convinced the parental care is perfect, cannot know this. ${ }^{3}$ Instead, s/he unknowingly modifies her/his inborn ideal for selfcaretaking to conform to and recreate the parental care $\mathrm{s} / \mathrm{he}$ is receiving. Accordingly, children acquire ways of making themselves as unhappy as they have become accustomed to feeling in the relationship with the caregiver. Common examples in preschool children are headbanging and frequent accidents. Once a child has developed unrecognized needs for unhappiness, these can be expressed in self-sabotaging motives for 1) self-caused unhappiness (e.g., picking scabs), or 2) motives for experiences of destructive pleasure (e.g., continuous thumbsucking). Even so, the child retains a motive for constructive pleasure with which s/he was born.

Destructive self-regulatory patterns are commonly exacerbated in reaction to a crisis experience. According- ly, in crisis treatment the therapist aims to strengthen the client's latent motives for constructive self-regulation, which in turn helps the client to shift from destructive to constructive forms of self-regulation. In crisis treatment based on intrapsychic humanism, the client discovers that s/he can regulate the therapist's caregiving responsiveness and, by so doing, finds that s/he can significantly enhance self-regulation of her/his well-being. The net effect of such strengthening of the client's motives for self-regulation is that s/he has a more stable inner wellbeing, is more able to make self-caretaking choices, and can pursue those choices more steadfastly.

From the standpoint of intrapsychic humanism, all young children are so intensely involved and in love with their parents that their entire self is built around the caregiving relationship. Accordingly, whenever a child has individual intrapsychic treatment, ideally the parents have an intrapsychic treatment or, at minimum, parental guidance counseling. This strengthens the parents' capacity for a conflict-free caregiving intimacy with their child and significantly remediates the environmental stressors on the child. Unfortunately, however, parents often will bring their child for treatment but refuse treatment or parental guidance counseling for themselves. While other approaches may assume that under these circumstances nothing can be done that will permanently benefit the child, as will be seen below, intrapsychic humanism offers an approach to child treatment that can be beneficial even under the suboptimal conditions of the parent's reluctance to get treatment or counseling for her/himself.

\section{Case Example and Crisis Treatment Principles}

\section{Beginnings: The First Interview}

Offering the child a treatment relationship. Rose had called the social worker requesting treatment for her three-year-old son Paul. ${ }^{4}$ In this phone contact, she said that her pediatrician had told her that Paul needed psychological help. She said that she and Paul's father, Leon, had been experiencing severe marital conflicts, had recently separated, and were getting a divorce. Rose had decided to divorce Leon after a five-year marriage because he had been severely emotionally abusive to her and to Paul; the emotional abuse had begun to escalate to physical abuse of her, although she emphasized that Leon had never hurt Paul physically. Leon had a history of arrests for driving under the influence of alcohol, and 
he refused to get any psychological evaluation or assistance from this social worker or others (such as divorce mediators) who had repeatedly sought to engage him in treatment. Rose said that Paul had developed very serious symptoms in the three months since their separation, including withdrawal, temper tantrums, enuresis, depression, and night terrors that were so acute that he would not sleep alone. She said to the social worker, "I hope you can get him to talk; he won't talk with me anymore."

At the first interview, the social worker introduced herself to Paul and explained that they would spend some time together while his mother waited outside. Paul readily came into the social worker's office and went straight to the dollhouse.

P: What's this (pointing to a chair in the dollhouse)?

SW: That's a chair. But I can see you wonder what all this is about. I'm a social worker who helps children with their feelings. Your Mom told me that she and your Dad are separated and it might be feeling hard for you.

P: (Reaches into the house, gets the father doll, who slams the door. He tries to open it.) I can't get it. Help.

SW: (Opens the door.)

P: (Rings the bell. He has the child doll outside the house. He whispers that the social worker should say, "Who's there?")

SW: Who's there?

P: Paul. (He has the child doll, who is still outside, slam the door; then the child doll rings the bell again.)

SW: I can see that part of you wants to come in but part of you doesn't.

P: (Rings bell.)

SW: What happens then?

P: He comes.

SW: Who's that?

P: The Dad. (He has the child doll ring the bell. The father opens the door and says, "Hello, Paul." Paul smiles, then slams the door on the father.)

Go upstairs. (The father goes upstairs, Paul is shutting the door vehemently.)

(Has father drive away in the car. Then he comes back, and they all sit at the table.)

They're having dinner.

SW: Who's there?

P: Mom, Dad, me - the baby.

SW: How do they feel?

P: Good.

SW: Maybe part of you wishes everything could be back the way it was when you were a baby and your Mom and Dad were together.

P: I want to get in there, I can't get in; I can't get in.
SW: It's terribly hard to be shut out and not be able to get in. Those are just the very hard feelings that we can help you with Paul.... (He has the baby crawl, and the baby cries. Then Paul for the first time, sheds the protective layer of using dolls to express his feelings; he crawls up to the social worker's chair, crying.)

P: I want my bottle.

SW: Can you tell me why you're crying?

P: (Pretends to be sucking on a bottle and then throws it away.)

SW: It looks like you feel so very, very bad.

P: He died. The baby died.

SW: Gee, the baby felt so hurt and bad he felt like dying?

P: Yes.

SW: Wow, I can hear you're feeling so, so badly.

P: He broke the bottle.

SW: He was mad and threw it away. But I wonder if sometimes when you feel so bad, it feels like your fault?

P: Yes.

SW: Children often feel it's their fault when their parents get divorced. But it's not your fault. It could really help you a lot to come here and have help with those feelings that the pain you're feeling is your fault.

P: (Crawls around by the chair and gets some candy that's on the table.) I want some.

SW: Okay.

P: (eats the candy and looks at the social worker.)

The social worker formulated the treatment contract with Paul based on the feelings that he was showing her he wanted help with painful feelings of being shut out and of not being able to have his family the way he wanted it. She said that it was terrific that he could tell her about those feelings because their relationship could help him with those feelings. The social worker also said she would meet with Paul's mother and see if she could bring him once a week so they could do this together. Paul enthusiastically agreed. moment.

SW: Gee, l'm afraid we're going to have to stop in a

P: What's this? (the puppets)

SW: To play with if you like.

P: I want to.

SW: Terrific. I'll talk with your mother and tell her I think I can help you. I won't tell her any of the things you told me today - those are just between us. But for now, we have to stop.

P: No.

SW: I know it's a loss when we have to end, espe- 
cially since you have gone so long without having anyone to talk to about this, and you'd like to stay. I sure hope we can see each other again, too.

If we look at the first interview with Paul from his point of view, Paul has the experience of meeting the social worker, entering the therapy room, wanting to share his feelings via the doll house, asking for the social worker's cooperation (when he asked for help, and again when he whispered "say 'who's there"), and discovering that the social worker is responsively available to his motives concerning when and how to share his feelings. Clinicians using other approaches to child treatment commonly believe that in order to strengthen the child's ego or help the child gain insight, they need to suggest games or stories to the child in order to get her/him to focus on and discuss specific content (Gallagher, Keavitt, \& Kimmel, 1995; Gardner, 1986). The rationale is that the child needs to discuss certain content so that the therapist can interpret it or, alternatively, in the case of a narrative approach, that the child needs to share her/his thinking so that the therapist can assist him/her in developing a more coherent narrative (Palombo, 1991). Because such approaches require the child's communication about certain topics in order for the therapeutic action to occur, the child is generally guided to talk. Thus, in the context of having only a few sessions, there may be added pressure on the child to cover content surrounding the event precipitating the crisis reaction.

By contrast, intrapsychic humanism proposes a therapeutic action based on the confirmation of the client's capacity for constructive self-regulation. Intrapsychic humanism thus holds that when the therapist introduces a motive to focus or not focus on certain content (e.g., to play certain games or tell specific stories), the client is forced to react to the therapist's motives with the effect that $\mathrm{s} / \mathrm{he}$ does not discover her/his own self-regulatory motives. Accordingly, the social worker never suggests that Paul address any particular content, nor does she lead him to play particular games or with specific toys. Intrapsychic humanism points out that every person understands who s/he is via her/his self experience in the caregiving relationship, and by letting Paul set the agen$\mathrm{da}$ and pace of the treatment process, the social worker helps Paul discover his own capacity to make use of the treatment relationship for constructive self-regulation.

A psychological crisis reaction is commonly triggered by a loss of gratification of an important motive. The immediate precipitant for Paul's crisis reaction was his parents' conflicts and divorce, which caused multiple losses to Paul's experience of his own capacity for pleasurable self-regulation - e.g., he did not have his family all in one home as he wanted, and rather than having a harmonious family eating together happily, he was often caught in his parents' conflicts. His parents' separation was making him unhappy, and since children interpret any aspect of their subjective experience as reflective of what their parents want them to feel, the crisis event was strengthening motives for unhappiness that Paul had already developed. Because the client in a psychological crisis is feeling her/his self-regulatory capacity dented by events precipitating the crisis, it becomes all the more important to provide the client with an opportunity to regulate the agenda and pace of the caregiving relationship and to thereby experience her/his own capacity for constructive self-regulation.

Respecting the child's motives occurs within the limits of responsible caregiving. For Paul, the unhappiness characteristic of the crisis reaction did not take the form of destructive acting-out against others or things, but some children do express their unhappiness in those ways. It is important that the therapist find creative ways to respect the child's motive to share and receive help for her/his unhappiness; at the same time, the therapy should not give the child the frightening experience that s/he can hurt her/himself, others, or the office. So for example, one child, when unhappy, would try to punch or scratch the therapist. The therapist would intercept his punch and gently hold his hand, explaining to him that while she couldn't let him hurt himself or her, it was important that he feel free to share his feelings of unhappiness. As the treatment progressed, the therapist could also help the child understand why s/he was experiencing those motives at the time. Whether or not the child's unhappiness takes the form of destructive acting-out, it will be seen below that respecting the child's motives is the foundation for a therapeutic process in which the child, of her/his own accord, chooses to relinquish the pursuit of motives for unhappiness that are expressed in symptomatic, dysfunctional behavior.

From the principle of respecting the child's motives, it follows that the therapist would offer the child the opportunity to make a treatment contract for her/himself. While it is true that children are brought by their parents and so come to the treatment relationship as involuntary clients, therapists using other approaches have assumed that this means the child either cannot make her/his own treatment contract (Fraiberg, 1987) or that the contracting process is irrelevant with children (Greenspan \& Greenspan, 1991). From the standpoint of intrapsychic 
humanism, however, offering the child the opportunity to express a motive to continue the treatment relationship is the crucial foundation for the therapeutic action. Most often, if the treatment is conducted in a way that respects their motives, children are active, willing, and enthusiastic participants.

\section{Understanding the Child's Communications}

The crisis reaction. From what Paul tells the social worker at the very start of the interview, we see that he views himself as outside the family house, feels angry with his family (e.g., slamming the door), and feels abandoned by his father. He wants to have a happy family life but feels desperately unhappy because he is unable to make that happen ("I want to get in there. I can't get in; I can't get in"). He is clearly communicating both the central loss of the crisis event (his parents' separation) and his feelings of rejection, anger, desperate yearning, and self-blame in reaction to it. To understand Paul's crisis reaction, one begins with the common observation that such reactions are prompted by a loss of a gratification that is significantly meaningful to the client.

While all crisis theories hold that crisis reactions are commonly prompted by a loss, they differ in how they explain the psychological impact of the loss. According to intrapsychic humanism, when a client does not have a stable capacity for constructive self-regulation, s/he must rely entirely on interpersonal successes and other gratifications (such as succeeding in academic or athletic pursuits), which provide a temporary, unstable inner wellbeing. A loss, then, has both the meaning of the loss of an important gratification and also echoes all the way down to the client's core experience of her/his own selfworth and capacity for constructive self-regulation. Thus, for Paul, the experience of his parents living apart meant not only the loss of missing his father's presence in his home, but also that he was unappealing and incapable of bringing about the pleasure of his father's responsive care (indicated by his frequent statements, "I can't get in ...").

Intrapsychic humanism explains Paul's crisis reaction. Whenever there is core inner pain, a client's motives for social, cognitive, and physiological gratifications can be understood as organized in a dynamic balance between two centers of gravity: 1) motives for constructive pleasure, also called the pleasure-seeking self (for example, motives to have harmonious friendships, to enjoy learning, and to take care of one's body), and 2) motives that cause the client to misidentify unpleasure as pleasure, or self-sabotaging motives (Pieper \& Pieper, 1990, p. 201). Examples are motives for conflict, alienation, failure, physical self-abuse, and motives for destructive types of pleasure (e.g., reckless bike riding). Children, who are often more in touch with their experience of being motivated to do what observers see as self-sabotaging, will commonly say about behaviors such as headbanging and other forms of self-injury, "I like to do that; it feels good..."

In a crisis reaction, the pain of the loss strengthens the client's acquired needs for unpleasure, thereby further undermining his/her efforts at constructive self-regulation. For example, Paul's motive for alienation, expressed in his throwing away the bottle and then blaming himself for having done that, represents a need to make himself unhappy. $A$ vicious circle ensues because the self-caused unpleasant experience seems to confirm the client's helplessness and incompetence, as occurred when Paul then blamed himself for his unhappiness ("He broke the bottle").

Assessing the client's motives. In assessment, the social worker wants to discern those aspects of the client's self-sabotaging needs that pose the greatest threat to the client. The social worker could see from the first interview that Paul was reacting to his parents' divorce with intense feelings of self-rage and anger, which he found very frightening. In response to his parents' inability to provide the caregiving he needed, Paul, like all young children, was unable to identify the cause as his parents' personal difficulties. He concluded that his parents were perfect caregivers who were perfectly devoted to him, and that he deserved the unhappiness he was experiencing, which in turn strengthened his motives to treat himself that way. Paul had acquired a hegemonic experience of himself as angry, unsatisfied, excluded, and rejected. By talking about the baby who died, Paul was also showing the social worker the alarming extent of his depression - that his fantasies had turned to thoughts of death as a way to relieve his distress.

The harshness and depth of Paul's need to make himself as unhappy as he experienced his parents as making him was evident in the first session, and was represented, for example, in the intense, almost continual conflicts between the people in his play. At the same time, Paul also showed the social worker the strength of his motives for constructive self-regulation. He expressed his desire to get help for himself when he came into the office without hesitation and immediately began sharing the pain he experienced in his family by enacting the scenes in the dollhouse. He responded to the intimacy that the social worker offered with increased motives for direct caregetting pleasure, when, for example, he turned to her pre- 
tending he was a baby who wanted his bottle. These motives continued when he returned to being his own age and agreed to the therapeutic contract the social worker offered him.

\section{... unless a social worker understands} why the client's symptomatic behavior is a meaningful response to the crisis event, s/he will not be able to help the client understand the client's need for such behavior.

In the assessment process in intrapsychic humanism, the therapist ascertains the balance between the client's self-sabotaging needs and the client's motives for constructive self-regulation. The therapeutic relationship is an ideal context for such an evaluation because the caregetting pleasure the client experiences inevitably triggers in her/him what intrapsychic humanism calls "aversive reactions to pleasure. An aversive reaction occurs when the client's acquired needs for unhappiness compel the client to respond to pleasure by creating experiences of unhappiness" (Pieper \& Pieper, 1990, pp. 218-9). Put differently, because of the competition between the client's inborn motives for constructive pleasure and acquired needs for unpleasure, a pleasurable experience will signify loss to the (often unconscious) part of the self that has acquired needs for unpleasure. These needs then assert themselves with increased intensity. Evaluating the nature, duration, and intensity of a client's aversive reactions to care-getting pleasure aids a therapist in making critical decisions, such as whether the client will need inpatient or outpatient care. One of the more significant aversive reactions that occurred in Paul's first interview was when he became angry and threw away the bottle. The ongoing gratification of the therapist's responsive caregiving had stimulated his motive for constructive self-regulation to the point where, via pretending he was a baby, he could show how much he wanted caregiving (represented by the bottle). His needs for unhappiness were frustrated and, to satisfy them, he threw the bottle away and blamed himself, saying "he broke it."

To help Paul begin to find a way out of the vicious circle of reactive negativity, the therapist's response was designed to help him see that she could understand but did not share his self-blame. Paul's response to the therapist's caregiving bodes well for his capacity to benefit from treatment: his motives for constructive self-regulation regained control over the aversive reaction, and he asked for more nurture from the therapist through the medium of asking for the candy the social worker had available for him. In addition to assessing aversive reactions as part of a diagnostic therapeutic process, a therapist can track aversive reactions to evaluate a client's progress, because they occur throughout the treatment, as will be seen below.

\section{The Interview with the Parent}

During her interview, Rose told the social worker that Paul had been made the center of her conflicts with Leon. For example, Rose said that she frequently became enraged with Leon when he called to speak with Paul, and she noticed that Paul was manifestly frightened by their arguments. Rose also expressed a concern that parents who have conflicts about caregiving intimacy often feel: "Maybe I care too much about him." The social worker responded, "That's impossible. Giving him all the care you can will only help him."

Although Rose was making the crucial commitment to get help for Paul, and although she could agree to telephone contacts with the social worker, she reacted with a self-punitive feeling that getting help for herself would be more than she deserved. Despite the obvious turmoil and misery in her personal life, Rose said, "I have friends to talk with though, and Paul doesn't. If he gets better, I'll be fine." She adamantly rejected the idea of getting help for herself, despite the social worker's efforts to engage her. She was experiencing a profound aversive reaction. Rose's very deep aversive reaction to the pleasure represented by the therapeutic relationship did not bode well for her capacity to remain committed to the treatment process.

Many treatments using other approaches would come to a halt once a parent refuses treatment for her/himself, as those models hold that a child cannot be treated unless the parent is treated. Intrapsychic humanism, by contrast, emphasizes that clients of every age have a motive for improved self-regulation, which can be stimulated and strengthened. For example, a treatment relationship can help a child to cope more effectively with a difficult environment (including acting on the environment in her/his own behalf). Accordingly, the social worker's treatment plan was that she should be available to Rose by telephone to help her with any recurring crises. Part of the reason for this decision was that it was clear Rose needed help, despite her statement that she did 
not want treatment for herself, and the social worker hoped the telephone contacts might stimulate Rose's motive for her own treatment or parental counseling. The social worker also told Rose that Paul would need at least three months of once-weekly therapy (i.e., twelve sessions), at which time they could re-evaluate the need for further treatment.

\section{The Ongoing Therapeutic Process}

\section{Treatment Planning}

Crisis intervention necessarily involves triage, or prioritizing the client's problems and helping him/her with those that are the most toxic first. In order to carry out the triage process, the social worker needs to ascertain those self-sabotaging motives that pose the greatest danger to the stability of the therapeutic alliance and other aspects of the client's well-being. Such planning helps the social worker choose where and how to focus in responding to the client's complex and plentiful communications.

Some other approaches to child diagnosis are based on lists of symptomatic behaviors that de-emphasize or even completely leave out the child's subjective experience (Conners, 1969). Yet, unless a social worker understands why the client's symptomatic behavior is a meaningful response to the crisis event, s/he will not be able to help the client understand the client's need for such behavior. In the absence of such an understanding, the social worker can only resort to interventions that approach or manipulate the client's behavior from outside the client's subjective experience. Such interventions have the serious disadvantage of failing to produce lasting change, because by definition they do not touch the regulatory aspects of the client's subjective experience. Consequently, when the therapy ends or the environment changes, the client is likely to develop symptoms again. Further, the authoritarian attitude that can underlie such approaches undermines the client's experience of self-regulation. Finally, such approaches leave the clinician with, at best, a fragmented and partial understanding of the client's subjective experience, which predisposes the clinician to feel puzzled and even frustrated with the therapeutic process and, often, with the client.

Intrapsychic humanism helps the social worker understand the way in which symptomatic behaviors express motives that provide a (psychopathological) selfregulatory self-experience. Then, the social worker has a base from which s/he can offer an alliance based on her/his comprehension of the client's effort at self-com- forting in the face of the losses of the crisis event. An analysis of Paul's communications in the second interview shows how the therapist develops this understanding. Paul, just discovering that he now had the opportunity to get comfort for the pain of the losses he was experiencing with his parents, showed the social worker mother and father dolls in the same house, having dinner with the baby. The baby was "fine." Then Paul built two houses. One of them was made out of blocks that were balanced precariously and kept falling down. Paul grew increasingly frustrated and made small angry sounds.

SW: You feel angry?

P: Yes.

SW: Maybe you're also sharing that you feel very sad and angry that a house for your Mom and Dad together won't work out. It's terrific you're telling us about that.

The social worker used "us" to stimulate the child's reflective recognition that now the child has the opportunity to express himself and to experience the social worker listening to his motives.

Next, Paul made a pile of blocks, stood on them, and put the tiny parent dolls, who were "asleep," far below him. Then he had them "die." Paul said "Spooky" killed them and that Spooky was very angry because he felt so left out. When the social worker asked him if he was feeling left out and angry, Paul said, "um hum." The social worker, recognizing that Paul wanted help with his fear that his angry feelings would hurt those he cared for, responded, "It's just the thing to do, to tell us about those hurt and angry feelings. Your angry feelings won't kill anyone, but it sure can be hard on you to feel bad about being angry. It's terrific you're telling us both about feeling angry and also that you feel bad about feeling angry."

Paul's most crippling self-sabotaging response to the turmoil in his family was his negative feelings about himself in reaction to his own anger. Although social workers generally cannot change aspects of a crisis event and cannot eliminate the pain that results from losses, they can help the client with how s/he experiences her/his painful reactions to the crisis event. For instance, Paul feared his reactive anger would kill his parents, and he felt so badly about being angry that he had to experience the angry feelings as being caused by a ghost he called "Spooky" rather than by himself. Understanding this dynamic was essential to treatment planning.

As was noted above, Paul had night terrors, and he related that he was constantly afraid of ghosts. Paul's fear of his anger about his parents' separation was being attached to all his experiences of his anger - a common 
process. Through her responses to the anger he expressed in the treatment relationship, the therapist could help Paul respond differently to his anger, giving him an alternative way to handle his angry feelings that he could apply in every situation.

Accordingly, moments when Paul shared his angry feelings and his self-blame about them in the therapeutic relationship were especially fruitful. As is often the case, Paul's anger was aggravated in reaction to loss. At the close of the second session, Paul communicated how angry he felt when the session ended. When the social worker said that they would have to stop, Paul told the social worker to be the policeman puppet while he was the bird puppet; then his bird hit the policeman. The social worker said to Paul, "And maybe you also feel angry we have to stop for now. I'm so glad you're letting me know that." Paul agreed. Because Paul's angry feelings were usually expressed indirectly, either through his behavior or through projections in the form of the ghosts that frightened him almost constantly, an important therapeutic goal was to help him know that he could share the angry feelings with the social worker, experience the comfort of the therapist's responsive reflection, and find that there could be a more pleasurable alternative for regulating his angry feelings than pushing them off onto a bird or a ghost. In concert with the emphasis on giving the child the experience of being able to regulate the caregetting pleasure in the treatment relationship, notice that the therapist did not provoke or abet the child's anger. Further, in making the interpretation that the child was angry, the therapist was staying very close to what the child was communicating to ensure that the child would experience the therapist as responding to the child's communications.

As the treatment progressed, Paul was increasingly able to share the depth of his anger at feeling rejected by his father. He experienced some relief at being able to communicate this anger, sometimes by stomping around the room, sometimes by kicking over some toy baskets or pounding on the dollhouse. An important distinction needs to be made here, since other approaches to child crisis intervention, following psychoanalytic theory, emphasize abreaction or catharsis as part of the therapeutic action (Sugar, 1988). From the standpoint of intrapsychic humanism, if the therapist actively encourages the client's affective abreaction s/he is goading or stimulating the client's needs for unhappiness, which can cause the client to become more overwhelmed and regressed. Moreover, if the social worker has an agenda with regard to which feelings the client should express, the client may conclude that the social worker is interested in hearing only parts of her/his subjective experience. This will reinforce the client's own pain-driven needs not to recognize particular motives as part of her/his self-experience, and thus will keep those motives outside of the client's regulatory control.

\section{The Therapeutic Action}

The therapeutic action in intrapsychic crisis treatment occurs as the client experiences being able to cause the therapist's responsiveness to all the client's feelings, especially his/her feelings about the loss prompting the crisis reaction. Accordingly, it is important to avoid shutting off aspects of the child's subjective experience by encouraging or discouraging the child's expression of any particular affective states. The social worker's praise of Paul for sharing his feelings was not limited to moments when he shared his anger, but included times when Paul shared other feelings, such as closeness, pleasure, sadness, and fear. The social worker aimed not to encourage the discharge of affect, but to help Paul share his feelings in the context of a reflective caregiving relationship that fosters an internal base for constructive self-regulation.

In contrast to intrapsychic humanism's focus on the client's self-regulatory self-worth and inner balance of motives, many approaches to crisis intervention conceptualize the therapeutic action in terms of remediating the client's lack of learned skills (such as deficits in problem solving or ego defenses) to help the client cope more ably with the crisis event. From the vantage point of intrapsychic humanism, however, efforts at cognitive restructuring can be problematic. The client's self-sabotaging motives can cause the client to experience the therapist's corrective or educative efforts as confirming the client's inadequacies, reinforcing the client's sense of inferiority, self-blame, and alienation in relationships. Clients may comply with the therapist's efforts and may appear to be changing, but such compliance generally represents selfabnegation and does not result in lasting internal change. When the client's self-sabotaging motives are neither understood nor accounted for, efforts at change via cognitive remediation will be either entirely obstructed by the client's intensely reactive negativity or, if change appears, it will be short-lived. In a crisis treatment based on intrapsychic humanism, the therapist helps the client to tip her/his psychological balance in favor of her/his more constructive self-regulatory capacity, most importantly by giving the client the experience that her/his constructive, pleasure-seeking motives can effectively cause the 
superior pleasure of the therapist's responsive availability (for example, allowing the client to regulate the agen$\mathrm{da}$ and pace of the treatment relationship), whereas the client's self-sabotaging motives actually rob the client of the pleasure available with the therapist by making the client feel isolated or angry.

Normally, a crisis treatment lasts anywhere from one to approximately fifteen sessions. During this time, part of the social worker's responsibility is to evaluate the need for more extensive care and, when indicated, to communicate this to the client and the family. After ten sessions, it became clear that although the balance between Paul's constructive and self-sabotaging motives was clearly shifting in favor of his pleasure-seeking motives (for instance, he was manifestly less withdrawn, more communicative, no longer experiencing temper tantrums, was beginning to be able to sleep in his own bed, and was no longer experiencing suicidal ideation), the severity of his self-sabotaging motives indicated a need for further treatment. Paul clearly wanted to continue the treatment, and when the social worker told Rose her assessment and recommendation that the treatment should be extended, Rose concurred and, fortunately, had the resources to continue the treatment.

A key principle of the therapeutic action in intrapsychic treatment is that once the client is able to distinguish between self-sabotaging motives and motives for constructive self-caretaking, s/he can then choose between these motives. As the client experiences the more genuine pleasure that results from choosing motives for constructive self-caretaking, s/he increasingly chooses those motives, which in turn strengthens them. As a consequence, clients naturally lose interest in and forego the self-sabotaging motives that caused the symptomatic behaviors.

The following example illustrates this therapeutic principle. One of Paul's major symptoms was his conflict about using the washroom. Rose said that he often wet his pants. At the beginning of the treatment, each time he went to the washroom he was afraid that ghosts or some other scary creature would hurt him. In session nine, Paul showed his therapist that he was worried about flushing the toilet. He had difficulty relieving himself and consequently remained uncomfortable for long periods and had to return to the washroom frequently. In addition, after he did use the washroom he often reported that he was dirty. The beneficial impact of the therapist's interventions was evident as Paul's symptoms steadily remitted. In session thirteen, after saying that his foot hurt and asking for her help in "jumping," Paul told the social worker that he had a dream about her in which he was jumping and she was helping him. Over the course of the treatment, Paul grew considerably freer to experience natural pleasure in taking care of his body. During session seventeen, Paul, showing that he was no longer frightened about using the washroom, asked the social worker to walk on tip-toe with him to the washroom, and shared the pleasurable fantasy that he was Bugs Bunny while the social worker was Tweety Bird. Once he was in the washroom stall, Paul said,

P: Now I'm peeing. Can you hear?

SW: Yes I can.

P: Now I'm pooping. Can you hear?

SW: I sure can.

P: Isn't it great? Listen ... [He's clearly delighted. He finishes.] Now let me get water and wash my hands.

An important way the therapist makes the therapeutic action possible is by focusing on the process meaning of the client's communications. The process meaning is the meaning the client's communications have in terms of her/his conflicting motives for closeness to or distance from the care-getting pleasure available in the therapeutic relationship (Pieper \& Pieper, 1990, p. 276). For example, the process meaning of Paul's initial communications about being shut out of his home and rejected by his family can be understood as a reaction to the new therapeutic relationship, in which he is afraid that he will be rejected and shut out by the therapist. Other approaches to child treatment focus interpretations on aspects of the child's behavior and/or the dynamics of the child's relationship with others (Brems, 1993; Gallagher, Keavitt, \& Kimmel, 1995; Greenspan \& Greenspan, 1991). By contrast, the social worker using intrapsychic humanism observes the child's behavior and her/his communications about relationships, focusing on what these communications indicate about the child's experience of distance or closeness with the therapist. The social worker takes seriously the client's descriptions about events in her/his life, such as when a child is thrilled about making a new friend or upset because he fell off his bike. In addition, by focusing on the process meaning, the therapist perceives how the client is using the therapeutic relationship for self-regulation. In listening to the process meaning, the social worker is especially attentive to whether the client turns to the therapeutic relationship for comfort of losses, and when the client experiences heightened dysphoria due to an aversive reaction.

As part of listening for the process meaning, the therapist helps the client develop constructive self-regulatory control over her/his aversive reactions, which is a key to 
the therapeutic action. Aversive reactions to the caregetting pleasure with the therapist (such as when Paul threw away the bottle in the first session) are optimal opportunities for that process to occur. For instance, as Paul became better able to experience the comfort of the caregiving mutuality for the losses he was experiencing, he also experienced aversive reactions. In session nine, he shared with the therapist feelings of loss (his wish that his parents were still together, frustration about their separation, and fear of his reactive anger). He clearly felt comforted, and then wanted to leave the room and sneak up on his babysitter, Julia. Sharing with Paul her understanding of the process meaning, the social worker articulated both Paul's pleasure-seeking motives and his reactive needs to cause himself unhappiness, and helped him avoid the loss of removing himself from the treatment room: "Maybe when one part of you wants to share and have help with how hard it feels, another part of you gets scared and feels like leaving. We have some more time today." Clients need the social worker to point out an aversive reaction because it operates invisibly: although an observer can notice that the individual shifts suddenly from a deeply pleasurable to a dysphoric or dissociated state, the person having the reaction generally loses sight of the fact that $\mathrm{s} /$ he felt good and then becomes submerged in the negative experience. By tracking the client's aversive reactions, the therapist can evaluate whether or not the treatment is effective. If the treatment is beneficial, the client will gain regulatory control over her/his aversive reactions, and the client's aversive reactions will decrease in intensity and duration.

\section{Helping the Client with Ongoing Aspects of the Crisis Situation}

Other treatment approaches, including problem solving and cognitive behavioral models, hold that the child must participate in a process of problem solving and insight concerning the crisis. When the child shares feelings metaphorically (feelings of fear, being intruded upon, etc.), these communications may not be seen as furthering the therapeutic action, but as distractions (Kelley \& Wallerstein, 1977) or as a premature abreaction that impedes the treatment (Gallagher, Keavitt, \& Kimmel, 1995). Because intrapsychic humanism is based on the child's experience of the caregiving relationship, it is ideally suited to help therapists make use of all of the child's communications. So in the following example, a scribble Paul makes turns out to be his initial effort at a communication of one of the most painful aspects of the crisis.
Paul, who by session seventeen was increasingly turning to the social worker for psychological caregiving that he knew he needed but was not getting enough of at home, described his parents' preoccupation with their conflicts as being like a spiderweb that "grabs and holds," and hurt him:

P: [Goes in and lays down on the couch and sighs.]

SW: Gee, I can see it felt so very hard this week that you just feel very tired.

P: Oh, oh, oh. [He draws a scribble.]

SW: Gee, what is it?

P: A spiderweb.

SW: What does it do?

P: Grabs and holds.

SW: Does it hold things together?

P: No.

SW: Does it grab and hurt?

P: Yes.

SW: Who made the web?

P: Mom and Dad.

SW: Do you want to tell me what happened?

P: They were fighting.

SW: Gee, sounds like when Mom and Dad fight it feels like getting stuck in a spiderweb. It hurts very much?

P: Yes. [He makes a swimming pool out of blocks and steps on the blocks.] Ouch!

SW: I can see that hurts. Is that your Dad's swimming pool?

P: Yes. Oh. [groans]

SW: Did it feel so very hard with your Dad?

P: Yes. [He closes his eyes and sighs, rocking slightly. Then he opens his eyes and looks at the social worker.] Mommy, rock me.

SW: You're right, Paul. I'm a mommy for your feelings.

A child's experience of stressors other than the event precipitating the crisis reaction, such as a new experience like starting school, can be magnified during a crisis period. When Paul started his new preschool, he found it very difficult. In session fifteen, the social worker gave Paul a loss because she responded to his sharing that he was starting preschool out of the assumption that he was looking forward to it. Despite that loss, Paul persisted in trying to get her help for the pain he was actually feeling about starting preschool. He turned out all the lights in the room. The social worker understood the process meaning of Paul's action and said, "maybe you're letting me know I'm in the dark about how you're feeling." When Paul nodded she said, "I bet that was feeling hard, 
and it's terrific you could tell me that." Then Paul said, "Let's lay on the floor and do homework together. Get the crayons," using the caregiving mutuality to help himself adapt to the new situation.

This example illustrates perhaps the most challenging therapeutic task. A client's heightened dysphoria can be caused either by a loss, including a therapist's caregiving lapse, or by an aversive reaction. The challenge for a therapist is to distinguish between these two causes. This task is especially difficult because social workers aim to take the best care of clients and generally are unaware of many of their caregiving lapses. Listening carefully to the process meaning of clients' communications helps social workers learn about themselves and identify their caregiving lapses. One indicator that the social worker was on the right track in interpreting Paul's turning out the lights as a reaction to her caregiving lapse came when she gave Paul a reflection for the lapse; Paul's alienated feeling abated, and he resumed his focused positive involvement in the caregiving mutuality as a base for his constructive self-regulation ("Let's do homework together").

With respect to the very painful interpersonal situation Paul was communicating through the metaphor of the spider's web, the social worker provided as much assistance to Rose as she could accept (within the parameters of the treatment contract, which required that the therapist offer Paul a caregiving relationship that he could experience as not tangled up in the conflict between his parents). To illustrate, Rose wanted the social worker's help in safeguarding Paul during his visitations with his father. Since Paul had consistently made it clear to the social worker that he was afraid of Leon (although there was no evidence of physical or sexual abuse), and given Leon's continued refusal to get help, the social worker wrote a letter to the court supporting Rose's request that Paul's visitations with Leon be monitored more carefully. Moreover, the social worker encouraged Rose to see divorce mediators again and made sure Rose knew where she could get that help.

\section{Evaluating Treatment Effectiveness}

The social worker used a naturalistic approach to evaluate the treatment and did not alter the therapeutic process by introducing into the treatment instruments that have a research rather than therapeutic aim (Heineman Pieper, 1994). Accordingly, the social worker's data were process recordings completed after the sessions were over (Tyson, 1995). As part of assessment and treatment planning, the social worker formulated change indices with which to measure whether crucial treatment goals were being met. For evaluating the efficacy of a crisis treatment based on intrapsychic humanism, a key issue is whether the client is more able to make use of the therapeutic caregiving mutuality for help with the crisis. To measure whether that goal was being met, the therapist examined specific change indices, developed as part of the dynamic formulations mentioned above. They were, first, whether Paul was increasingly able to bring to the therapeutic mutuality feelings of anger and loss. Second, the therapist evaluated whether Paul's pleasureseeking motives had attained sufficient regulatory control to make it possible for him to pursue age-appropriate functioning (e.g., using the toilet, being able to sleep in his own bed, going to preschool). Based on data obtained from the treatment sessions alone, it was clear that Paul's self-sabotaging symptoms (suicidal ideation, fear of ghosts, conflict concerning use of the washroom, difficulty sharing angry feelings, and withdrawal in response to loss) had remitted after twenty sessions.

The social worker also used Rose's descriptions of Paul's functioning as another perspective on changes in Paul. Rose reported that he was much more open in expressing his feelings, and also that he was more collaborative and affectionate. He regularly slept easily in his own bed and no longer seemed to be afraid of ghosts at night. He no longer wet his pants. When he was angry, he could openly share those feelings, and Rose reported that he was more easily soothed.

\section{Conclusion}

In response to Paul's progress, Rose's deep aversive reaction, manifest initially at the onset of the treatment, recurred. She believed that Paul no longer needed treatment. The time when a child's symptoms begin to improve is often a turning point for the parent. Despite the parent's best intentions, $s /$ he may have her/his own aversive reaction to the pleasure of the child beginning to recover. In response to the remission of the child's acute symptoms, some parents will seek treatment for themselves. Some are able to continue to trust the child's work with the social worker despite the discomfort they feel in another part of themselves. Others discontinue the child's treatment, which unfortunately is what Rose decided.

Within the month, Rose reported that she wanted to reconcile with Leon, and she did not want any kind of treatment. In session twenty-five, Paul came in and told the social worker that his mother had told him he no longer needed therapy and would not be coming any 
more. At the same time, Paul clearly communicated how much he felt he needed help ("I'm hungry; get the candy. I'm thirsty. Can you get me some water?") and how deeply confused and distressed he was by his mother's remarks, saying that he was afraid "spiders" would "come in and kill us." By talking with Rose, the social worker was able to forestall the termination for five sessions, but then Rose insisted that she was bringing Paul for the last time.

Social workers who treat children often find that the child's treatment is terminated despite their best efforts to provide the care that the child needs and wants. When a child's treatment has to end under such painful conditions, a question frequently arises: Will it be harder on the child, who now has less denial about his own pain and his parents' pain, to have to live in a family with parents who are not amenable to change? We know that people benefit from psychological support, and we never think about curtailing emotional support to an adult simply because the adult will have to continue to live in a difficult situation. Further, researchers have found that children feel helped by treatment they were given for many years after the sessions have ended, even when the children were young and the treatments were brief (Kelly \& Wallerstein, 1977).

The social worker can use a forced conclusion of the treatment as an occasion to help the child strengthen her/his capacity to mourn loss by bringing the feelings of loss to the therapeutic relationship instead of pursuing self-sabotaging motives. Accordingly, it was extremely important that the social worker help Paul know that his reactive feelings of confusion, anger, and betrayal were understandable and legitimate, and at the same time help him to anticipate his need for self-blame and other selfdestructive responses to the loss.

Many evaluations of child treatment have overlooked children's opinions about the usefulness of the treatments they receive, but the precept of respecting the child's motives underscores the importance of including such opinions in the evaluation. Throughout the treatment, Paul had communicated the value his therapy had for him. One of the most significant expressions of such feelings occurred toward the end of his treatment. He had started to bring a small knapsack to each therapy session, in which he would store the candy the social worker gave him. Paul told the social worker that Rose took the candy away from him, put it in a locked box in the garage, and parceled it out to him during the week. $\mathrm{He}$ found this excruciatingly painful. During the last session, when the social worker was helping him with his feelings about the loss of his treatment ending against his wishes, he showed her how important it was to him to hang on to what he got from the treatment. He had brought all sorts of small objects in his knapsack, including a comb, tiny dolls, rubber bands, paper clips, marbles, and playing cards. As the session drew to an end, he took the candy the social worker gave him out of its bag. Then, slowly and deliberately, he took everything out of his knapsack and buried the candy very carefully amidst and under the other objects, so that it was clear it would be almost impossible to sort out the candy pieces.

P: It's gold.

SW: Yes. You're keeping it down deep.

P: I'm going to save it. The wrappers, too.

When the social worker commented that both of them would keep their relationship in their minds always, Paul said, "yes," and with a very determined look, he stuffed his "gold" down deeper into his knapsack.

I have chosen to present this case because I wanted to share with you Paul's courage and determination to have the social worker's help in developing a mind free of pain. Children no longer have to struggle alone against the kinds of obstacles Paul faced. With the understanding of children's subjective experience that intrapsychic humanism affords us, and its appreciation of the abiding impact of caregiving relationships, social workers have a potent new way to fulfill our mission of helping young children.

\footnotetext{
${ }^{1}$ The tenets of intrapsychic humanism are explicated in Intrapsychic $\mathrm{Hu}$ manism: An Introduction to a Comprebensive Psychology and Philosophy' of Mind, by Martha Heineman Pieper and William Joseph Pieper.

${ }^{2}$ In the intrapsychic humanism theory of child development, psychopathology, and treatment, this is also called effective agency.

${ }^{3}$ It is critical to state that intrapsychic humanism separates moral turpitude (or blame) and cause, and emphasizes that all parents want the best for their children and should nor be blamed for their child's psychological pain. Thus the statement that psychopathology is caused by sub-optimal caregiving is not equivalent to blaming parents.

${ }^{4}$ In accord with professional ethics and statute, identifying information and other aspects of the case process that do not affect the scientific meaning of the case data have been changed to maintain client confidentiality. ${ }^{5}$ Heineman Pieper makes the point that to introduce research instruments into the treatment process, such as scales or tape recorders, that lack intrinsic therapeutic benefit, alters the therapeutic process. Such research is an example of interventionist (by comparison with naturalistic) research. The point is not that naturalistic research is intrinsically superior to interventionist research, but that both forms of research are valuable and their respective merit in designing a research study can be determined in relation to the problem under study.
} 


\section{References}

Berliner, L., \& Wheeler, J. R. (1987). Treating the effects of sexual abuse on children. Journal of Interpersonal Violence, 2, 415-434.

Boyd-Webb, N. (1994). School-based assessment and crisis intervention with kindergarten children following the New York World Trade Center bombing. Crisis Intervention, 1, 47-59.

Brems, C. (1993). A comprehensive guide to child therapy. Needham Heights, MA: Allyn \& Bacon.

Cheyne, J. A., \& Rubin, K. H. (1983). Playful precursors of problem solving in preschoolers. Developmental Psychology, 19, 577-584.

Conners, C. K. (1969). A teacher rating scale for use in drug studies with children. American Journal of Psychiatry, 126, 884-888.

Famularo, R., Kinschereff, R., \& Fenton, T. (1990). Symptom differ ences in acute and chronic presentation of childhood post-traumatic stress disorder. Child Abuse and Neglect, 14, 439-444.

Fatout, M. F. (1993). Physically abused children: Acrivity as a therapeutic medium. Social Work with Groups, 16, 83-96.

Fenby, B. (1992). Book review: "Intrapsychic humanism: An introduction to a comprehensive psychology and philosophy of mind," Smith College Studies in Social Work, 62, 195-197.

Fraiberg, S. (1987). Some aspects of casework with children. In L. Fraiberg (Ed.), Selected writings of Selma Fraiberg. Columbus. $\mathrm{OH}$ : Ohio State University Press.

Freud, A. (1952). The role of bodily illness in the mental life of children. Psychoanalytic Study of the Child, 7, 69-81.

Freud, A., \& Burlington, D. (1943). War and children. New York: Ernst Willard.

Gallagher, M., Keavitt, K., \& Kimmel, H. (1995). Mental health treatment of cumulatively reperitively traumatized children. Smith College Studies in Social Work, 65, 205-237.

Gardner, R. (1986). The game of checkers in child therapy. In Game play: Therapeutic use of childhood games. New York: John Wiley \& Sons.

Greenspan, S. 1., \& Greenspan, N. T. (1991). The clinical intervieu' of the child. Washington, DC: American Psychiatric Press, Inc.

Heineman Pieper, M. (1994). Science, not scientism: The robustness of naturalistic clinical research. In E. Sherman \& W. J. Reid (Eds.), Qualitative research in social work. New York: Columbia University Press.

Ishibashi, N. (1991). Multicultural students: What do they want? School Social Work Journal, 16, 41-45.

Juhasz, S. (1995). Coping skills of ritual abuse survivors: An exploratory study. Smith College Studies in Social Work, 65, 255267.

Kelly, J. B., \& Wallerstein, J. S. (1977). Brief interventions with children in divorcing families. American Journal of Orthopsychiatry, 4, 23-29.

Lewis, D. (1992). From abuse to violence: Psychophysiological consequences of maltreatment. Journal of the American Academy of Child and Adolescent Psychiatry, 31, 383-391.

Lindemann, E. (1965). Symptomatology and management of acure grief. In H. Parad (Ed.). Crisis intervention: Selected readings (pp. 17-22). Milwaukee, WI: Family Service America.

Palombo, J. (1991). Neurocognitive differences, self cohesion, and incoherent self narratives. Child and Adolescent Social Work Journal, 6, 449-472.

Parad, H., \& Parad, L. (Eds.). (1980\}. Crisis intervention, book II. Milwaukee, WI: Family Service America.
Pieper, M. H., \& Pieper, W. J. (1990). Intrapsychic humanism: An introduction to a comprebensive psychology and philosophy of mind. Chicago: Falcon II Press.

Pieper, M. H., \& Pieper, W. J. (1992). It's not tough, it's tender love. Child Welfare, 71, 369-377.

Pieper, M. H., \& Pieper, W. J. (1995). Treating violent, 'untreatable' adolescents: Applications of intrapsychic humanism in a statefunded demonstration project [Alumni Centennial Invitational Lecture Series, University of Chicago, School of Social Service Administration]. In K. Tyson (Ed.), New foundations for scientific social and behavioral research: The heuristic paradigm (pp. 455472). Needham Heights, MA: Allyn \& Bacon.

Pieper, M. H., \& Pieper, W. J. (1999). Smart love: The compassionate alternative to discipline that will make you a better parent and your child a better person. Harvard Common Press: Boston.

Rapoport, L. (1970). Crisis intervention as a mode of brief treatment. In R. Roberts \& R. Nee (Eds.i, Theories of social casework. Chicago: University of Chicago Press.

Sorenson, T., \& Snow, B. (1991). How children tell: The process of disclosure in child sexual abuse. Child Welfare, 70, 3-15.

Sugar, M. (1988). A preschooler in a disaster. American Journal of Psychotherapy, 42, 619-629.

Terr, L. (1990). Too scared to cry: Psychic trauma in childhood. New York: Basic Books.

Tyson, K. (1991). The understanding and treatment of childhood hyperactivity: Old problems and new approaches. Smith College Studies in Social Work, 61, 133-166.

Tyson, K. (Ed). (1995). New foundations for scientific social and behavioral research: The heuristic paradigm. Needham Heights, MA: Allyn \& Bacon.

Tyson, K. (1996a). Response to: Is it possible to generate any universal list of basic Human Behavior and the Social Environment (HBSE) concepts and principles that all students should learn? and Rebuttal. In M. Bloom \& W. Klein (Eds.), Controversial issues in human behavior and the social environment. Needham Heights, MA.: Allyn \& Bacon.

Tyson, K. (1996b). Advancing clinical social work: Prior approaches and a view towards the future based on intrapsychic humanism. Orig. of Dalla teorie psicologiche all'Umanesimo Intrapsichico: prospettive per il Clinical Social Work. In Il lavoro socio-clinico dell-assistente sociale. Daniela Piscitelli (Ed., translation by A. Carbone). Milan:Vita E Pensiero.

Zambelli, G. C., \& Clark, E. J. (1994). Parentally bereaved children: Problems in school adjustment and implications for the school social worker. School Social Work Journal, 19, 2-15.

Katherine Tyson is associate professor, Loyola University of Chicago, School of Social Work, 820 N. Michigan Avenue, Chicago, II.

Original manuscipt recieved: December 15, 1997

Accepted with revision: August 27, 1998 